\title{
Safety security and risk management - aftermath bhopal disaster
}

\begin{abstract}
On 2-3 December 1984, methyl isocyanate (MIC) leak from Union Carbide factory (UCIL) pesticide plant in Bhopal, Madhya Pradesh was considered as one of the worst industrial disaster in the world. They killed 10,000 people and 500,000 people suffered with poisoning effects. The disaster is due to backflow of water into a tank of MIC due to some routine pipe maintenance. In this paper, events leading to the disaster, other major death rolls and their causes are discussed. The poor site selection and response of industries for risk documentation and management are carefully analyzed. Various implemented acts and rules and regulatory activities related to industrial safety from Bhopal disaster is well examined. Effective management techniques for analyzing, modeling, monitoring, predicting and preventing the accidents and for safety assessment are investigated. Safety measures implemented in other small scale and medium scale industries are reviewed. Finally major lessons learnt from this disaster and ideas for better preparedness to initiate industrial safety and disaster management have been addressed.
\end{abstract}

Keywords: disaster, industrial safety, risk management, security standards, industrial regulations
Volume 2 Issue 6 - 2017

\author{
Rajkumar S \\ Department of Electronics and Communication Engineering, \\ Madanapalle Institute of Technology \& Science, India
}

\author{
Correspondence: Rajkumar S, Department of Electronics \\ and Communication Engineering, Madanapalle Institute of \\ Technology \& Science, Madanapalle, India; \\ Email s.rajkumar@iitkgp.ac.in
}

Received: May 30, 2017| Published: June 29, 2017
Abbreviations: MIC, methyl isocyanate; UCIL, union carbide India 1td; RDX, research development explosive; HAZOP, hazard operability studies; PHA, preliminary hazard analysis; IHA, interface hazard analysis; O\&SHA, operating and support hazard analysis; QRA, quantitative risk analysis; RA, risk analysis; MORT, management oversight risk tree analysis; SCIL, safety critical item list; DSR, design safety review; OSR, operational safety report

\section{Introduction}

The exponential growth of the human population, coupled with new ways to attain higher standards of living through technological advances, have resulted in the widespread growth of industries at the global level in the past few decades. This has resulted in rapid industrialization. But the safety measures in these workplaces have taken into least care and these unsafe environments have created many industrial disasters. The majority of industrial disasters have caused fires, explosions and toxic emissions and their damage to the people and the environment were very heavy. Few of those occupational health hazards and their effects have been identified; their damage potential and remedial measures have not been still quantified. Yet, another year passes by, the world's worst ever chemical disaster, which occurred in Bhopal, commemorated annually. After the leak of methyl isocyanate (MIC) on December 2-3, 1984, from a Union Carbide factory killed a total of 16,000 people $^{1}$ and injured half a million, Bhopal has become synonymous symbol with an absence of industrial safety measures.

As a result, the nodal ministries of various countries were pushed to initiate massive measures to ensure safety. The Bhopal disaster in India triggered outrage over the whole world and inspired it to learn lessons on industrial safety. The 1984 Bhopal gas leak released Union Carbide's pesticide-an estimated 42 tons of toxic methyl isocyanateand 500,000people were exposed to MIC. Such accidents occurred when safety measures failed. The number of victims was exceedingly large. The lessons learnt from this incident were the only way to avoid future such accidents and explosions.

\section{Anatomy of a domino accident}

In order to promote industrialization and attract large multinational corporations (MNCs) to India, Union Carbide Corporation was allowed to construct a pesticide manufacturing plant, named Union Carbide India Ltd (UCIL) at Bhopal in India. A runaway chemical reaction due to excessive ingress of water to the methyl isocyanate (MIC) tank and non-functional safety systems created an uncontrollable exothermic reaction that unleashed $\mathrm{MIC}^{2}$ to atmosphere continuously for about two hours through the vent line. This catastrophic effect killed more than three thousand people. The main reason for the disaster was the negligence of safety survey warnings which popped prior the disaster.

\section{Hazardous site location}

The outdated industrial location theories have placed the production facility close to either dwelling areas or markets, regardless of the environmental conditions. This was the main reason for Bhopal disaster in which the industry was located near a thickly populated area and the victims were too high. Sometimes, wrong combinations of industries were established in close proximity. ${ }^{3}$ For example, reports show that a viral vaccine plant and a Research Development explosive (RDX) company were located in close proximity in Jaipur. In another report, Chembur in Mumbai have confronted environmental and pollution problems due to the effluents from oil refineries, petro chemical plants, fertilizer plants, and thermal power plants and several other smaller hazardous units were located around the city. Recently, a research was carried out in the U.S. ${ }^{4}$ regarding the location of ten thousand schools across the country. The research published their bombshell report that many schools are located within a mile from chemical facilities. The research also reported that 4.6 million children schools were located within a mile of a facility that stores potentially risky chemicals. We can prevent the massive death 
roll by relocation of industries from the densely populated areas to reduce the chance of public affliction and casualty from the future hazardous accidents and explosions.

\section{Response of industries}

In this section, reliability of various MINs is analyzed. Major industrialized states show glaring omissions in providing sufficient mitigation facilities at the sites of industries. Coincidentally, the numbers of accidents in these states are also high. Many journalists had warned about the potential dangers that the Bhopal carbide plant posed to the city, ${ }^{1}$ but the response was too light. Increasing casualization of safety concerns is a sad reckoning. If the safety infrastructures are kept at a poor level, there will be loss of people's life in this fiercely competitive global industrial environment. The industrial disaster of Bhopal was due to its worst management, maintenance and non compliance of industrial safety rules. ${ }^{2}$ Such poor level of observance of safety norms, under- staffed and underresourced working environments does not augur well for the future industrial safety. So the industries have to change their attitude and they have to recognize in improving safety for their benefit and safety of their workers.

\section{Major disasters-aftermath Bhopal}

Worst massive disasters aftermath Bhopal in human history was due to poor safety and security and absence of risk management in their industrial sites. The explosion in a fertilizing factory in Toulouse (2001) killed 29 people. The explosion ${ }^{5}$ were due to the rejects of ammonium nitrate granulates stored in a warehouse. Texas City oil refinery explosion (2005) killed 15 workers and injured more than 170 others. The explosion ${ }^{6}$ was a direct result of a malfunction of hardware, technical failures, human errors, as well as organizational and regulatory failings. Various surveys and assessment reports had been warned about the safety culture. But the management had a dead response to them and postponed the major upgrades to the refinery. Explosions at China-based Jilin petrochemical's aniline plant (2005) killed 5 workers and also 100 tons of benzene and other poisonous chemicals are leaked over the Songhua River in north eastern China. The explosion + was due to the open rectification tower valve which raised the temperatures and thereby the nearby equipments and storage tanks caught fire and exploded.

Shipping containers holding gunpowder at the Evangelos Florakis (2011) naval base on Cyprus exploded..$^{7}$ The gunpowder that were being stored for $2^{1 / 2}$ years in the sun self-detonated killed 13 people and injured 61 due to the failure of security and poor stockpile management. This accident appeared to be the result of "criminal negligence". Hube Globe chemical plant explosion (2012) released highly toxic eight tones of hydrofluoric acid. The leak ${ }^{8}$ killed five workers at the plant and severely injured 18 people. Geismar La Williams Olefins chemical plant fire and explosion ${ }^{9}$ killed 2 workers and 114 were injured. They released more than 31,000 pounds of toxic volatile organic carbon material chemicals which includes propylene, ethylene, propane and benzene.

Accident due to a rupture in the heat exchanger caused a vapor cloud which was ignited by an unknown source, causing the explosion. Danlin chemical plant explosion at Oklahoma (2013) due to heating up pressurized containers are the major disasters ${ }^{10}$ due to human negligence and poor safety standards. Thus safety rule breakers are always an accident maker. The Elk River chemical spill (2014) has happened in U.S. state of West Virginia ${ }^{11}$ due to the lack of inspection.
Crude 4-methylcyclohexanemethanol (MCHM) was released from the holes in the tank into the Elk River from a Freedom Industries facility.

\section{Risk documentation and management}

Industries should invest more on risk minimization to make accidents costlier. If accidents are costly then its chances of occurring will be lesser. In fact, there should be safety documents for the view of public so that public will check often on regulatory bodies. This will also educate public and help in bridging the gap between the risk perceived and actual risk. ${ }^{12}$ Safety discipline involves a total change of mindset that can be invoked by apparently creating strong awareness list on improving industrial safety and disaster management. Once Industries follow the safety disciplines, it will automatically pave their way to tangible and intangible benefits. Risk documentation has been done by US experts for Bhopal plant warned about the chance of accident. But the management ignored the safety recommendations ${ }^{3}$ and the emergency procedures were never implemented which led to the Gas leakage.

Various acts and rules were passed after the Bhopal disaster in all the countries. ${ }^{1}$ The major rules which were passed in India after the Bhopal disaster to ensure safety and to control disasters: a)Bhopal Gas Leak Disaster Act (1985), b)The Environment (Protection) Act (1986), c)Criminal liability provisions of the Environment Protection Act, (1986), d)Factories Act (1987) e)The National Environment Appellate Authority Act (1987) f) Hazardous Wastes rules (1989), g) Manufacture, Storage and Import of Hazardous Chemicals (MSIHC) rules (1989), h)The Public Liability Insurance Act (1991), i)The National Environment Tribunal Act (1995), j)Chemical Accidents rules (1996), k)Provision in Chemical Accidents Rules (1996) and National Green Tribunal Act (2010).

\section{Lesson learnt and recommendations}

Several lessons can be learnt by analyzing this accident. Occurrence of this accident triggers the importance of safety management measures and also elucidates a minor change can leads to major consequences. The safety study committee, safety review committee and industrial safety division were appointed and created to identify major hazards and to study and review the requirement or availability of protection system and safety plant. ${ }^{1}$ The committee visited all installations and made recommendations for improvement of safety. Industrial safety regulations were revised. Industrial plant safety division advises generic industrial safety issues, recommends measures on industrial safety for prevention of accidents and providing guidance on the overall planning for prevention and protection. They also conduct review of the safety documents being developed on industrial safety. Industrial and fire safety review is created. They prepared a checklist for safety audit and carry out detailed study and assessment of the safety programme. The audit is required to be carried out by persons focusing on specific requirement, depending on the hazard potential of plant operation.

Occupational health and safety review and Advisory committee on occupational health are created to advice on occupational health aspects (Occupational Safety Manual BHEL). ${ }^{13}$ Including implementation of statutory provisions, occupational disease etc. Fatal accident assessment committee to assess fatal accidents and to arrive at the root causes of accident and preventive actions to be taken to avoid recurrence. Safety professional meetings are conducted to hold workshop at the individual units to discuss statutory requirements and 
their implications and to conduct a seminar on industrial safety. Safety awards for the industries are provided by the ministry of labor and employment for industrial safety excellence. The safety performance assessment based on computed value of safety numbers, preventive efforts and hazards as per a pre-defined computational methodology. Data's are collected in standard formats every year from all the industries for assessment of safety measures. Safety color codes ${ }^{14}$ are introduced to identifying the physical hazards and expediting fire fighting operation and other emergency services. Consider the fire prevention fighting (Red), machineries causing injuries (Orange), general caution (Yellow), first aid and personal protective equipments, e.g. - gas masks (Green), radiation hazards (Purple), housekeeping and traffic locations (Black and White) and caution or warning against starting equipment under repair e.g. -lifts (Blue).

\section{Management techniques}

Poor design of the gas scrubber, flare tower, water curtain and along with poor maintenance standards leads to this major disaster. ${ }^{2}$ Other countries and industries also created awareness, education, training and capacity development of mitigation and better preparedness to initiate industrial safety and disaster management. This disaster also paved a way to reliability, availability, maintainability and safety criterion importance to follow the effective management techniques ${ }^{12}$ like sole system hazard analysis (SSHA), hazard operability studies (HAZOP), preliminary hazard analysis (PHA), interface hazard analysis (IHA) and operating and support hazard Analysis(O\&SHA) to study about hazards. Quantitative risk analysis (QRA), risk analysis (RA), management oversight risk tree analysis (MORT), probabilistic risk assessment (PRA) and comprehensive risk management plan to analyze risks.

Safety assessment is done by systems plan (SSP), safety critical item list (SCIL), design safety review (DSR), operational safety report (OSR) and safety audit. Failures modes effects and critical analysis (FMECA), THERP and, fault tree and event tree analysis (FTA AND ETA) and fire explosion and toxicity index(FETI) for analyzing, modeling, monitoring, predicting the root causes of the disaster and preventing the risk and ensuring safety. Thus the business environment imperative to quantify their damage potential through computerized modeling results, identify hazards in plant operation and then remedial measures are practiced for risk minimization and control. They also increased their quality assurance activities (the management system built to ensure safety systematically) by safety preservation inspections.

\section{Metrics recommended}

Fatal Accident Rate (FAR) and Potential Loss of Life (PLL) are the commonly used metrics to avoid any risks [9]. FAR gives the expected number of fatalities per 100 million working hours. Potential loss of life is just the expected number of fatalities associated with certain activities, without taking the exposure, such as the number of person at risk or the exposure time, into account and often based on historical statistics. Unlike PLL, FAR takes exposure time into account. Probability of failure on demand (PFD) and Risk reduction factor (RRF) (1/PFD) are the quantitative measure for safety. Metrics for individual risk is calculated by Individual risk per annum (IRPA) which gives the probability that a specific individual will suffer a fatal accident during a year. SSI risks are higher as compared to big industries because of improperly designed facilities, untrained manpower. The key to combat industrial disasters management during emergency is through proper emergency preparedness. ${ }^{15}$ The government strengthened legislative provisions with regard to the sites of establishment of industries, relocation etc. Regulatory bodies should not work with a stick in hand but should work on a partnership basis (with the industries) and the approach should change effectively that persuade industries for self-regulation.

Industries should be encouraged to adopt new management tools such as ISO 9000, ISO 14001 etc. Management in small and medium scale sectors in which four significant causes will trigger safety. They are adequate process risk evaluation, adequate engineering to cope up with likely deviations, process demands and human factor. The safety measures in chemical and polymer industries includes developing EHS management systems (OSHAS 18000 and ISO 14000 certifications), safety audits during pre commissioning and post commissioning stages of the plant. They also depend on training programs for employees on PPEs, lead poisoning, equipment safety, HAZOP, conveyor safety, conduction work zone monitoring (RSPM, Noise and Heat) and developing safe operating procedures for all equipments inside the plant will prevent future disasters.

\section{Conclusion}

Thus the present scenario is in whatever position beyond debates and arguments, the rate and the magnitude with which accidents are affecting human lives; looks inevitable that the future may have lot to pay to galloping industrialization/liberalization. ${ }^{16}$ Multiple factors led to many eventual disasters and explosions. But the major root cause of the problem was the corporate cost-cutting techniques/methods, failure to invest in safety infrastructure and finally lack of safety culture to the employees/workers. "Time present and time past and both perhaps present in time future and time future contained in time past". Therefore the perspectives of disasters in the past will be best suitable vision to visualize the present and future industrial safety. Demand in industrial safety standards and safety planning, and threats about risk were the lesson learnt from this entire catastrophic event. The good news is that we know what to do and now we just have to do it because a little care makes accident rare. Thus emergency planning and safety management system be the tool to minimize the disasters like Bhopal in future. A good safety management system do everything right up to $99.99 \%$ and $0.1 \%$ becomes untoward incidence. This $0.1 \%$ needs to be focused now.

\section{Acknowledgements}

Very special thanks to the Head of Electronics and Communication Engineering, MITS for providing us with an excellent research environment and continuous motivation.

\section{Conflict of interest}

The author declares no conflict of interest.

\section{References}

1. India country report. Preparedness and response to chemical emergencies; 2009.

2. Ball R. Oscillatory thermal instability and the Bhopal disaster. Process Safety and Environmental Protection. 2011;89(5):317-322.

3. CSE draft dossier. Health and environment-a-environment and diseases; 2006.

4. Sheppard K. One year after texas disaster, Report looks at schools located near chemical facilities; 2014.

5. Barbier P. Urban growth analysis within a high technological risk area: Case of AZF factory explosion in tolouse (France). Ecole Nationale des sciences geographiques; 2003. 
6. Hopkins A. Failure to learn: The BP texas city refinery disaster; 2008.

7. Spencer R. Anger grows in Cyprus over 'criminal errors' behind explosion. The daily telegraph; 2011 .

8. Stafford N. Questions remain after huge hydrofluoric acid leak; 2012.

9. Schleifstein M. Geismar explosion and fire released more than 31,000 pounds of toxic chemicals, company reports; 2013.

10. Fiske MH. Oklahoma chemical plant explosions force evacuations; no injuries; 2013.

11. Gabriel T. Thousands without water after spill in West Virginia; 2014.
12. Modarres M. Risk analysis in engineering: techniques, Tools, and Trends. USA: CRC Press; 2006. 424 p.

13. Occupational Safety Manual BHEL.

14. Grimaldi JV, Simonds RH. Safety Management: Performance Measurement and Motivation. 5th ed. USA: Springer; 1989.

15. Singh UK, Dewan JM. Safety, Security and risk management. India: APH publishing company; 1996. 344 p.

16. Viswanathan P. Six still missing in Jilin Petchem blasts; 2005. 